\title{
Commentary
}

\section{Nepal needs midwifery}

April 2013 started the 1,000-day countdown to December 31, 2015 - the target date for achieving the MDGs (Millennium Development Goals). Since the MDGs were adopted in 2000 there have been many successes, but also disappointments. For example, as part of MDG5, Nepal is on target to achieve its reduction in Maternal Mortality Rate (MMR) and has been recommended for this. The Global Leaders' Council for Reproductive Health has nominated Nepal for an award for improving access to reproductive health. The MMR had declined from 539 to 281 per 100,000 between 1996 and 2006 [2], although that is still far too high.

A competent midwifery profession in Nepal Currently, over $64 \%$ of women in Nepal gives birth without a skilled attendant [3]. This is one of the factors leading to unacceptably high levels of maternal mortality and morbidity. As recently as $2006,81 \%$ of births took place at home, many without skilled health providers [4]. In 2011 two-thirds of birth (67\%) occurred at home. Of course home delivery is often to be recommended, but only if there a skilled birth attendant available to assist the women during a home birth. Unfortunately, many of the women in Nepal who deliver at home do so without a midwife who is the most appropriate skilled birth attendant, as she (or he) is able to recognize when birth is not progressing normally andknows when and how to refer to emergency obstetric care.

At the same time Nepal is not doing so well in increasing the proportion of women in childbirth attended by a skilledattendant. Apart from this wellrehearsed argument about the importance of the MDGs, there is a second growing maternityproblem, namely that of a growing epidemic of Caesarean Section, especially in the private hospitals of Kathmandu. Many middle-class educated women are ending up with unnecessary surgical interventions because doctors and hospitals earn more doing them than normal vaginal deliveries. Having midwives in the health care system would help to keep childbirth natural for many women, although midwives may have a difficult task trying to keep childbirth normal in private hospitals were every procedure brings in more money. The short animated film on YOU-TUBE entitled 'Midwives work' is a great starting point to highlight the importance of midwifery [5]. The film highlights the importance of the role of the midwife in reducing maternal and infant mortality as well as the issues and challenges they face. The midwifery profession world-wide plays a vital role in keeping birth normal and reduced birthrelated complications. The need for humanity and kindness is stressed as very important both for women and caregivers.

Nepal is not the only country lacking midwifery. The recently published report The State of the World's Midwifery: Delivering Health Saving Lives identified 22 countries, including Nepal (UNFPA 2011).Three pillars of a strong midwifery workforce were highlighted in this report: education, regulation and professional associations. None of these pillars alone will establish a strong midwifery workforce. If one of them is weak, the midwifery profession may still be weak, hence to create a midwifery profession, all three needs to be emphasized [6] Interestingly enough, as
Bogren $M^{*} . U$, Bajracharya $K^{* *}$, Berg $\mathrm{M}^{* * *}$, Erlandsson $\mathrm{K}^{* * * *}$, Ireland $\mathrm{J} * * * * *$, Simkhada $\mathrm{P} * * * * * *$ \& Van Teijlingen Edwin $* * * * * * *$.

* PhD student, University of Gothenburg, Gothenburg, Sweden,

** Maharajgunj Nursing Campus, Tribhuvan University, Nepal.

*** PhD, Professor, SahlgrenskaAcademy, Institute of Health and Care Sciences, University of Gothenburg, Gothenburg,

**** Associate Professor Malardalen University, Stockholm, Sweden, ***** Midwife; RCM Union Learning Rep \& Supervisor of Midwives. St Mary's Maternity Unit, Poole Hospital, UK \& Visiting Faculty, Bournemouth University, UK. $* * * * * *$ Senior Lecturer, School of Health and Related Research (ScHARR) University of Sheffield, UK \& MMIHS ******* Professor, Centre for Midwifery, Maternal \& Perinatal Health, Bournemouth University \& Visiting Professor, MMIHS, Tribhuvan University 


\section{Commentary}

early as 1928 Nepal sent four women for midwifery training to India, whilst in 1978 a two-year midwifery course was established in Nepal but after two years it closed down [7]. Again in 2006, the Government of Nepal realized the need of professional midwives as: (1) a crucial human resource for Safe Motherhood; and (2) leaders in midwifery in the country. Establishing this new cadre of independently practicing midwives is part of the Nepal strategic plan 2006-2011 and it is also mentioned in NHSSP II 2011-2015 and it is also incorporated in the latest UNFPA Country Program (CP7).

Women in Nepal delivering their babies without a skilled attendant may report traumatic physical and/or psychological experiences. At the same time educated urban women from well-off families may experience unnecessary Caesarean sections or other expensive medical procedures carried out to avoid spurious risks. If mothers do not feel they will receive safe and humane care they may present late or stay away from healthcare providers and receive no trained assistance. Lack ofemotional support is, of course, not only a problem in the less developed world. For midwives to display compassion towards women, organizations need to show the same towards them. The YOUTUBE film suggests that with good regulation, education, sensitive skilled respectful midwifery care mother and baby are more likely to live happy and positive family lives. The film ends with the statement: 'a better world starts with healthy families and strong relationships' Models of childbirth Many protagonists of midwifery make the distinction between a 'medical' versus 'social' model of childbirth [8].The social model of childbirth has also been referred to as a 'women-centred midwifery model' [9]. For those adhering to a social model, childbirth is in principle, and often in practice, a normal physiological process. This is the view of most midwives. For those adhering to a more medical model, childbirth is only safe in retrospect. Many doctors (but not all) and often nurses think and act according to a moremedical model of childbirth. Those following the medical model hold the belief is that every pregnant woman needs medical back-up, and to give birth in hospital 'just in case' something goes wrong. Whilst the social model suggests that pregnancy is a normal life event for most women, and although the pregnant woman may get regular check-ups and advice for most the pregnancy and birth will succeed without too much medical intervention.
The notion that pregnancy and childbirth are an 'illness', also affect the way one perceives 'risk' [10]. This is one distinction between nurses and doctors, on the one hand, who have been trained to deal with disease and illness and therefore are more likely to regard pregnancy and birth as pathological and risky. Whilst midwives, on the other hand, are trained to deal with healthy pregnant women, deal with minor problems associated with childbirth and refer serious problems to medical colleagues, and therefore are more likely to regard birth as physiological and low-risk. As Sandall [11] highlighted the social model so eloquently, it is widely accepted that every pregnant women needs a midwife, but not everyone needs a doctor. Midwifery education

Midwifery is already unique among health occupations worldwide that it has a globally agreed definition of the midwife and recommendededucation/ curriculum [12]. In Nepal midwifery is regulated under nursing, which is not conducive for the development of the profession and the government is keen to change this in the near future.

A basic step in developing any profession requires a comprehensive approach to strengthen the formal education for both students and teachers set out by a regulatory body, for example as a separate section of the Nepal Nurse-Midwife council. This is yet not achieved in Nepal. In a recent study it was found that Nepal has a variety of different educational levels level within nursing. However, none of the six curricula met all the requirements set out by International Confederations of Midwives [lbid] minimum educational standards, beside a Post-Basic Midwifery Program under development. To support the government in establishing a new profession and to ensure Nepal gets qualified andsafe midwives, it was suggested that a national strategybe developed, building on four strategic objectives in relation to training/education, legislation/regulation, deployment/utilization and strengthening of the professional association. Hence a task-force committee on Midwife Cadre and Education, chair by the Family Health Division director, has recently been set up within Ministry of Health and Population (MoHP).

The Midwifery Society of Nepal (MIDSON) is closely collaborating with other health care professional associations and the Government of Nepal to inform policy development. MIDSON, set-up with support from 


\section{Commentary}

UNFPA, works on a national, regional and district level to increase the technical component of midwifery invarious settings for the ANM (auxiliary nurse midwives) and nurses working in the field of reproductive health who can provide care, especially in remote and rural areas.

A feasibility study on professional midwives in Nepal was conducted in collaboration with the Family Health Division in 2012. The study recommended five potential higher education institutes that may (and could) start midwifery education.

MIDSON and other stakeholders such as fellow midwifery organizations abroad are all supporters to the Government of Nepal's strive to establish a midwifery cadre and initiate midwifery education according to the global ICM standards. Similarly, since 2012 the UK Royal College of Midwife (RCM) has twinned with MIDSON tohelp strengthen the association [13]. The overall goal of the project is to strengthen the midwifery associations using a series of workshops and a pool of UK volunteer midwives to help build capacity in leadership, advocacy and campaigning skills in Nepal. Figure 2.9 General population does not recognize midwifery

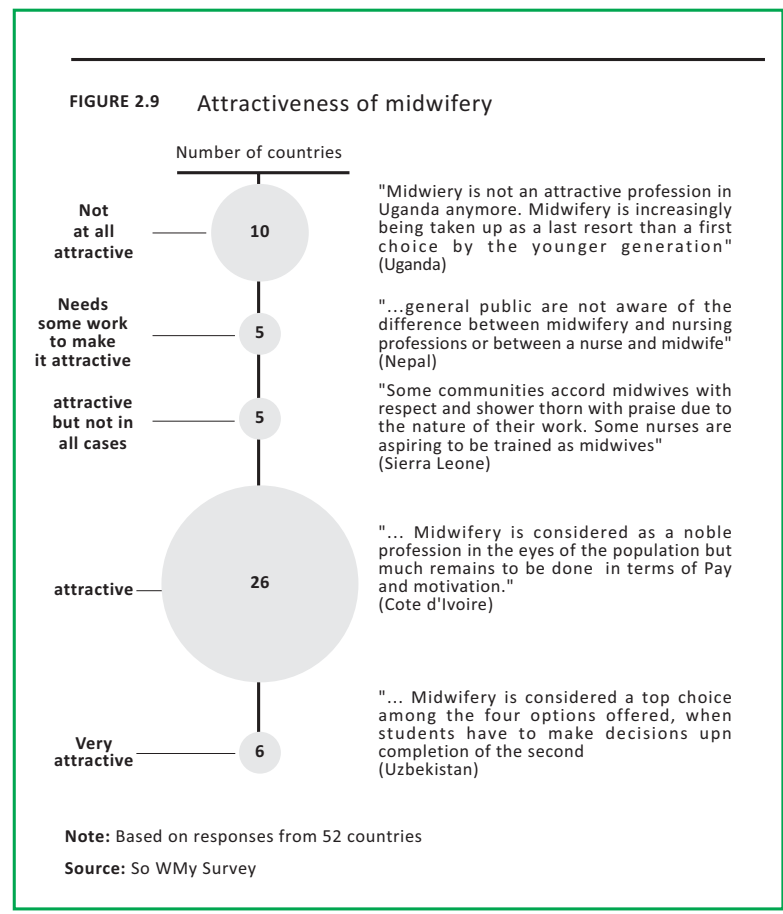

Source: State of the World's Midwifery Report (UNFPA 2011: p.27).
Perhaps is a key question to address is 'What distinguishes midwifery from nursing?' It has been suggested The State of the World's Midwifery Report (UNFPA 2011: p.27) that the general population in Nepal cannot distinguish between a nurse and a midwife (see Graph 2.9). Quality midwifery is a well-documented component of success in saving the lives of women and newborns. UNFPA (2011: 27) suggested that the general public in Nepal including many health professional cannot distinguish between the nursing and the midwifery professions or between nurses and midwives! Hence, the government of Nepal needs to take a lead and decide to introduce appropriate policy to support the SBA goal in the Nepal strategic plan for 2006-2017. With the technical support from the Regional Midwife Advisor/Asia to ICM, and following the leadership of the chief nurse, MOHP, strategic directions for midwifery inNepal have been developed. Regulation of the midwifery profession has been recognized as a key part of its practice in Nepal. Proper legalisation ensures this new cadre holding the title 'midwife' is guaranteed to have appropriate qualifications to work independently with normal pregnancy, birth, postpartum care, leadership, education and research within the area of midwifery. Legislation means (a) that those without the appropriate training cannot call themselves a midwife and (b) it raises the status of the profession.Final thoughts

Midwifery has great potential in Nepal. Skilled attendance at birth is still poor and the country needs an Action plan to achieve this aspect of the MDG goals. There is little capacity to train midwives in Nepal, but in September 2013 Patan Hospital is starting its midwifery training. Its curriculum for a Bachelor in Midwifery Education has been assessed against International Confederation of Midwives (ICM) Global Standards. A policy decision is needed from the Government of Nepal to establish this education of a new cadre of midwives, working independently according to their own rules and regulations, holding legalization and their own association, as it effects the existing nurse/midwife cadre, recruitment, retention and deployment as well. Once midwifery education has been established it is important for the government to create appropriate posts in its human resources and maternity care policies. Finally, we feel that the Nepal Nursing Council (NC) needs to creating a separate Midwife chapter or annex in their Act, which should recognize a midwife as an independent professional separately registered by the Nursing Council. 


\section{References:}

1. http://www.un.org/millennium/declaration /ares552e.pdf

2. Devkota, B., van Teijlingen, E. Understanding effects of armed conflict on health outcomes: the case of Nepal. Conflict \& Health.2010; 4 (20) www.conflictandhealth.com/content/4/1/20

3. Ministry of Health and Population (MOHP) [Nepal], New ERA, and ICF International Inc. 2012. Nepal Demographic and Health Survey 2011. Kathmandu, Nepal: Ministry of Health and Population, New ERA, and ICF International, Calverton, Maryland.

4. Ministry of Health and Population (MOHP) [Nepal], New ERA, and Macro International Inc. (2007). Nepal Demographic and Health Survey 2006. Kathmandu, Nepal: Ministry of Health and Population, New ERA, and Macro International Inc.

5. (www.youtube.com/watch?v=_NRfU3NRW_Y).

6. UNFPA (2011) The State of the World's Midwifery: Delivering Health Saving Lives. Web address: www.unfpa.org/sowmy/resources/docs/ main_report/en_SOWMR_Full.pdf

7. Minca M. Midwifery in Nepal: In-depth country analysis. Background document prepared for the State of the World's Midwifery Report 2011. Web address: www.unfpa.org/sowmy/resources/ docs/country_info/in_depth/Nepal_SoWMY InDepthAnalysis.pdf
8. van Teijlingen, E. A critical analysis of the medical model as used in the study of pregnancy and childbirth, Sociological Research Online.2005;

10 (2) Web address: www.socresonline.org.uk/10/2/ teijlingen. html

9. Berg, M., Ólafsdóttir, O.A., Lundgren, I. A midwifery model of woman-centred childbirth care - In Swedish and Icelandic settings Sexual \& Reproductive Healthcare,2012; 3: 79-87.

10. van Teijlingen E. The State of the World's Midwifery (Editorial) International Journal of Childbirth.2012; 1 (4): 214-215.

11. Sandall J. Every woman needs a midwife, and some women need a doctor too. Birth.2012; 39(4): 323-326

12. ICM (2011) International Confederation of Midwives: Global Standards for Midwifery Education (2010).Web address: www.unfpa.org/sowmy/ resources/docs/standards/en/R427_ICM_2011 _Global_Standards_for_Midwifery_Education_2010 _ENG.pdf'.

13. Anonymous (2012) Volunteer briefing, RCM Midwives Journal, 15(5):17. 